\title{
Recent advancements in shape optimization of aero spiked high speed re-entry vehicle using CFD
}

\author{
Harish Panjagala ${ }^{1}$, E L N Rohit Madhukar ${ }^{2}$, and I Ravi Kiran ${ }^{2}$ \\ ${ }^{1}$ Faculty of Mechanical Engineering, Koneru Lakshmaiah Educational Foundation, Vaddeswaram, Guntur, Andhra Pradesh, India - \\ 522502. \\ ${ }^{2}$ UG Scholar, Department of Mechanical Engineering, Koneru Lakshmaiah Educational Foundation, Vaddeswaram, Guntur, Andhra \\ Pradesh, India - 522502 .
}

\begin{abstract}
Due to increasing demand of High Speed Re-entry vehicles for Space activities within the world, a serious issue associated with the method of deceleration down a vehicle is by the intense heat generated because of development of stronger shocks at the nose. The price of thermal protection systems (TPS) to cut back the warmth generated by the return vehicles is extremely high. In this paper, the ultimate outcome is to cut back the aero heating which is achieved by introducing a spike at frontal region of the nose. Additionally, this spike avoids the deterioration and preserves the structural integrity of space vehicle over elevated temperatures. Further, four totally different geometries of tip specifically Blunt, Slender, Snap and Pan for the aerospike has been introduced and their impact on performance is evaluated and compared with the vehicle having TPS. Hence, usage of aerospike in return vehicles is the most successful and economical over different protection system.
\end{abstract}

\section{INTRODUCTION}

Re-entry Vehicle moves at terribly high speed in suborbital, that the wave generated is extremely robust and therefore the temperature behind that shock are greatly high. And this whole heat is transmitted to the vehicle body. It is required to scale back that heat from the body, and to dissipate the warmth in to air. These hot gases then flow subsequently within the boundary of the re-entry vehicle. Therefore, our major objective of reentry vehicle design is to act as protection of the vehicle to avoid from the severe mechanics of heating.

The objective of re-entry vehicle design is to reduce the warmth which fits into the vehicle and maximize that heat, that get into the air outside the vehicle. Thus, properly designed re-entry vehicle can act as protective covering and reduces the mechanics of air drag. Concerning the role of wind tunnels in fluid propulsive studies, in 1946 von Neumann aforesaid "Indeed, to a great extent, experimentation in fluid dynamics is performed under conditions wherever the underlying physical principles don't seem to be unsure, wherever the quantities to be ascertained are fully determined by known equations. Therefore, wind tunnels, for instance, are used at present, a minimum, as computing devices to integrate the PDE's of fluid dynamics."

F.F.J. Schrijer, F. Scarano \& B.W. van Oudheusden [1] conducted an experiment on Reattachment and Separation of Boundary layer on a Blunt shaped ConeFlare through QIRT. Transient HT measurements are administrated on the cone flare model during a short period hypersonic facility at Mach 9 through Quantitative Infrared Thermography (QIRT). Infrared vision camera was used to compute the temperature of surface and the temperature statistics were effectively related to heat transfer co-efficient specifically by two different reduction techniques. Z. Jiang, Y. Liu \& G. Han [2] conducted experiment to attain effective wave for reducing the drag underneath non-zero attack angles and additionally to avoid from severe aero heating, a new concept of the Non-ablative TPS for high speed reentry vehicles was planned and lateral jets are developed at the spike region as a renovating system of shock at front facet of hypersonic vehicles. The spike works as alternative of the bow shock at nose of a blunt vehicle, the lateral jet works to scale back the heat generated at the front of spike and diverts the shock away from the vehicle in conical shape. For the conceptual design and CFD validation the experimental visualization of flow \& pressure measurements was conducted in a hypersonic wind tunnel.

D. Dirkx \& E. Mooij [3] investigated the abstract design of a high-speed re-entry vehicle whose effect on performance is calculated by variation of shape and geometry. The two distinct categories of form optimisation in vehicles. .i.e. Capsule and winged vehicle. By victimization the local-inclination strategies and flight mechanics characteristics of these vehicles were analyzed. Entry flight regimes at Mach 3 were computed by assumptive boundary conditions. It has conjointly been studied that depending on the geometry of the structure there's important drop on pressure and temperature of body move in compressed medium however at stagnant purpose, at that the structure is modified between slendered nacile and once more compared to a blunt nacile based on the work of P. Harish et al [4]. It has been studied that there's a crucial role of temperature in supersonic and hypersonic flight period due to compressible effects and the thermal load reduction strategies like counter flow ejection of fluid 
jet of lower temperature collectively of the preventive estimation based on the work of Y.Y. Zeng et al [5]. It was additionally studied that there's sudden amendment of properties in fluid at the nacile portion of the re-entry vehicle because of operational speed and a spread of shocks like bow shock at nose of the vehicle. This case is analyzed by comparing with spike and without spike by observing decreasing pressure data in these highspeed vehicle based on work of C. Nataraj et al [6]. Flow analysis is performed using ANSYS FLUENT 17.2.

\section{MODELING AND ANALYSIS}

\subsection{Modelling by using Solid Works Software}

The profile of the winged hypersonic re-entry vehicle is modelled through Solid works 2016 tool. The dimensions taken for the high speed moving body is as shown in the fig2.1.1.

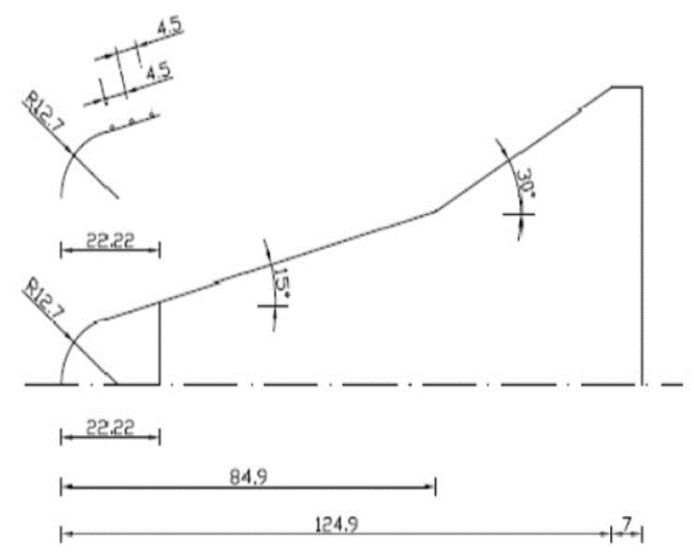

Figure 12 geometry of blunt body

Solid works 2016 modeling software has been used for constructing the appropriate 3D model with available dimensions. This can be done by revolving the geometry about the center line as shown in the figure 1.The Domain is created by using ANSYS FLUENT 17.2 Package. The face of the domain is extended by $1.25 l$ and behind the geometry byl $.5 l$ times. The top and bottom of the domain are enlarged by $1.25 \mathrm{l}$ times, where $l$ is the major length of the geometry model .i.e. $131.9 \mathrm{~mm}$.

\subsection{Meshing by using Ansys Fluent 17.2}

Before going to the flow analysis over the Vehicle the Vehicle model was imported from Solid works 2016 to ANSYS FLUENT 17.2. Before starting of the mesh the boundary layer is to be created around the Vehicle body. And then mesh the faces of the body by using ANSYS FLUENT 17.2. To create mesh of the domain all triangles method is inserted to map elements. Then quality of the generated mesh is checked.(figure 2\&3)

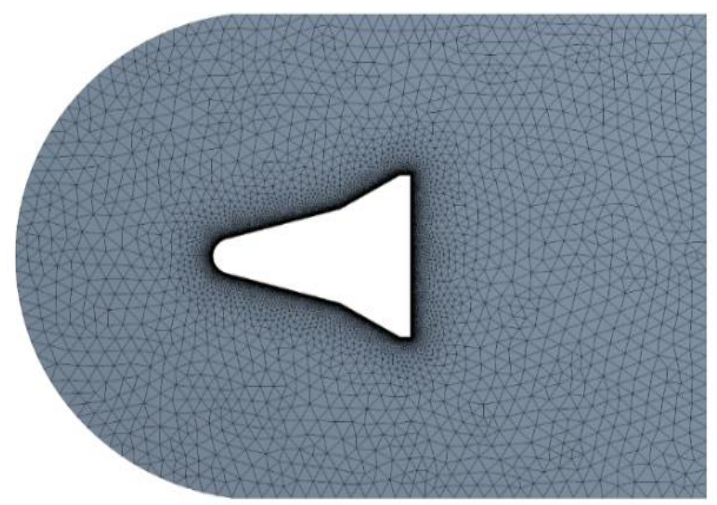

Figure 2 Mesh Model of the vehicle

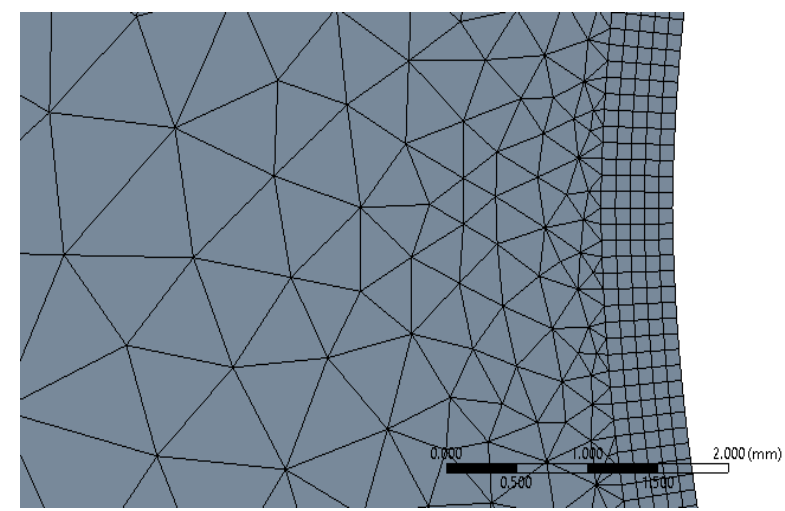

Figure 3 Boundary Mesh of the vehicle.

\section{.2.3 Boundary Condition Calculations}

After creating and meshing of the Vehicle in ANSYS then we are Exporting the model in to the ANSYS FLUENT 17.2 for the flow analysis for the flowing references.

At Mach number $(\mathrm{M})=9.1$

$\operatorname{Gamma}(\gamma)=1.4$

Stagnation pressure $=p_{0}$ in bar

Static temperature $=\mathrm{T}$ in Kelvin

Stagnation temperature $=\mathrm{T}_{0}$ in Kelvin

From Alan-pope formula:

$$
\begin{gathered}
p=\frac{p_{0}}{\left(1+\frac{\gamma-1}{2} M^{2}\right)^{\frac{\gamma}{\gamma-1}}} \\
=\frac{50}{\left(1+\frac{1.4-1}{2} 9.1^{2}\right)^{\frac{1.4}{1.4-1}}} \\
p=0.002205 \text { bar } \\
\text { (Stagnation Pressure) }
\end{gathered}
$$

From Wegener formula:

$$
\begin{gathered}
\log _{10} p=\frac{-605.4}{T}+4.114 \\
T=\frac{605.4}{4.114-\log _{10} 0.0022025} \times 0.5556
\end{gathered}
$$


$T=49.6763+273 \mathrm{k}($ Static temperature, $\mathrm{k})$

$$
\begin{aligned}
& T_{0}=T\left(1+\frac{\gamma-1}{2} M^{2}\right) \\
= & 49.6763\left(1+\frac{1.4-1}{2} 9.1^{2}\right) \\
T_{0}= & 873.446 \mathrm{~K}(\text { Stagnation temperature }, \mathrm{k})
\end{aligned}
$$

\subsection{Flow Analysis using Ansys Fluent 17.2}

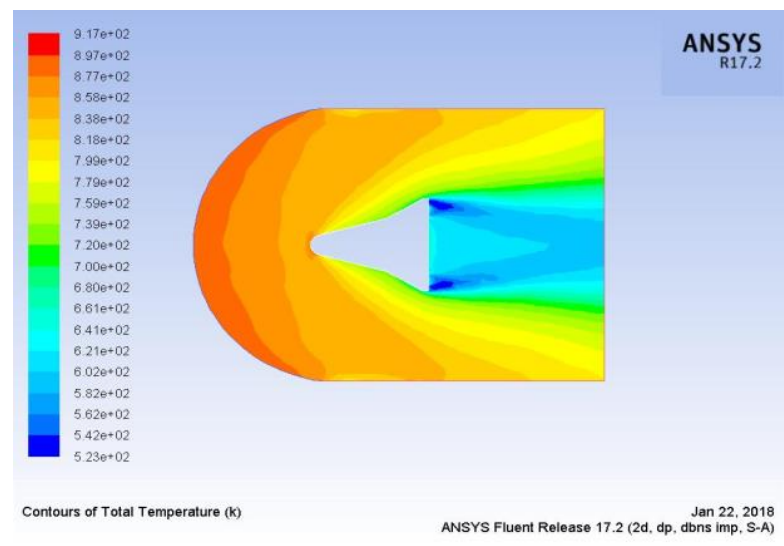

Figure 4 Temperature Contour of Blunt Body

The results for the Blunt re-entry vehicle are indicated. The temperature values along with corresponding contours and graphs are shown in figures $4 \& 5$.

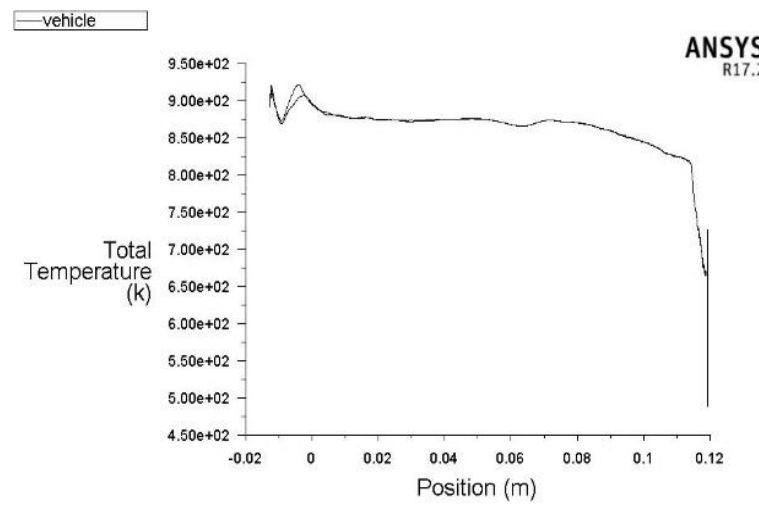

Total Temperature

ANSYS Fluent Release 17.2 (2d. dp. dbns imp, S-A)

Figure 5 Temperature Plot of Blunt Body

The temperature at the nose for the re-entry hypersonic vehicle was $908 \mathrm{k}$.(figure 5)

\section{VALIDATION AND VERIFICATION}

The experiment was done at Delft University of Technology, Netherlands. The wind tunnel was operated at a free stream Mach no. 9.1. The total pressure $P_{0}$ maintained in wind tunnel is ranging between 25 and 75 bars. A temperature controlled electrical heating system is used to heat the fluid (dry air) to a temperature of 873 $\mathrm{K}$. (figure 7)

The figure 6 shows the experimental scleren graph. This graph shows the shock wave pattern and the fluent generated shock wave pattern for the same experimental input so we are comparing the both graphs for validation.

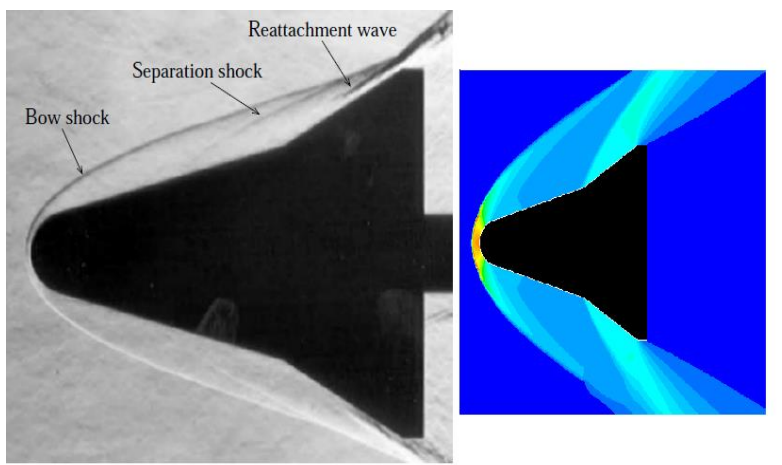

Figure 6 Contrast of Experimental Result with analytical result.

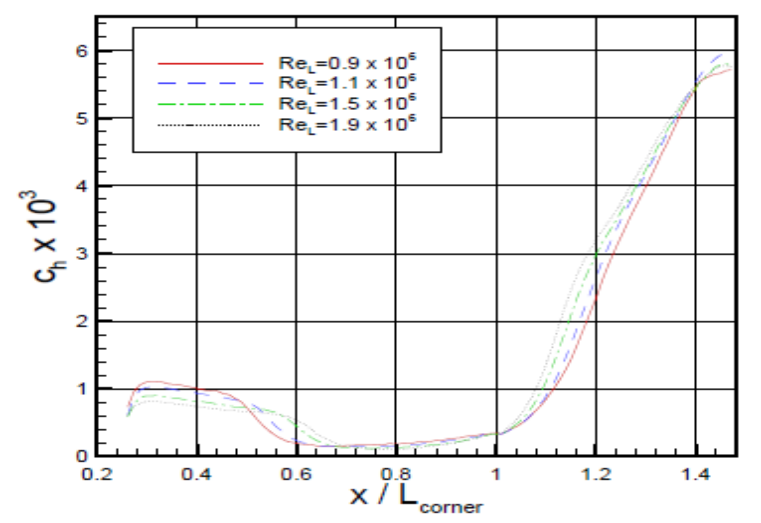

Figure 7. Heat transfer plot for the experimental model.

\subsection{Calculation of Heat Transfer Co-efficient} $\left(\mathrm{C}_{\mathrm{H}}\right)$ :

The Heat Transfer Rate is given by the relation

$$
q=\rho c l\left(\frac{d T}{d x}\right)
$$

Where the values of $\rho$ (density), $c$ (specific heat) and $l$ (thickness) of the skin are

$$
\begin{aligned}
& \text { ' } \rho \text { ' Stainless Steel density }=8000 \mathrm{Kg} / \mathrm{m} 3 \\
& \text { 'c' Stainless Steel specific heat }=502 \mathrm{~J} / \mathrm{Kg} \mathrm{K} \\
& \text { 'l', thickness }=10 \mathrm{~mm}
\end{aligned}
$$

And the co-efficient of heat transfer is calculated by using the equation

$$
\mathrm{C}_{\mathrm{H}}=\frac{\mathrm{dQ} / \mathrm{dT}}{\rho_{\infty} \mathrm{V}_{\infty}\left(\mathrm{h}_{0}-\mathrm{h}_{\mathrm{w}}\right) \mathrm{s}}
$$

Where, $\rho_{\infty}, U_{\infty}$, and $C p_{\infty}$ are called as density, velocity and specific heat at constant pressure respectively under free stream condition. Stagnation temperature is To and wall temperature is $T w$. From the figure shown in figure 8 it can be computed that there is less than 5\%deviation among Simulation and practical results. Hence, the taken case is validated. The simulation in continued in ANSYS 17.2 with the validated boundary conditions to decrease cost and save time. 


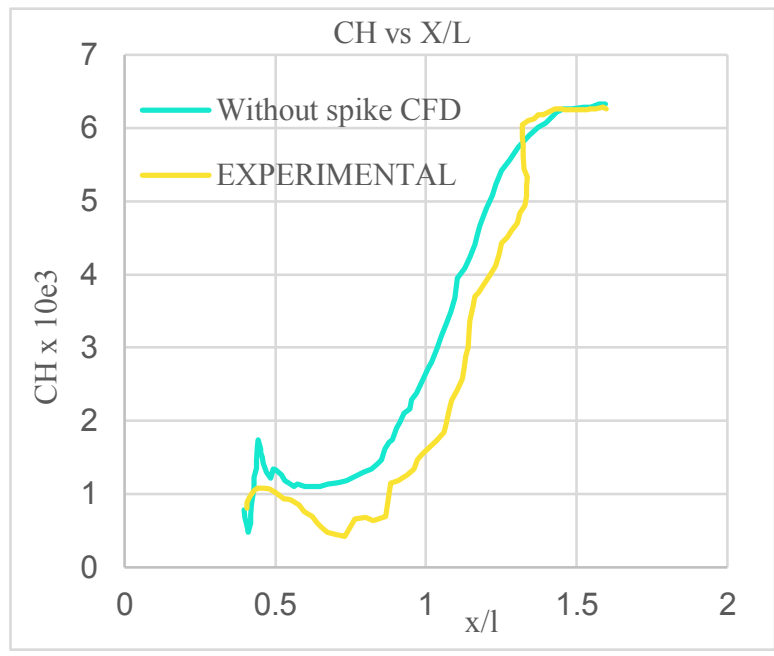

Figure 8. Experimental Result vs Simulation results

\section{TOPOLOGY OPTIMIZATION}

From the without spike results, it is observed that at nose region the temperature is very high, so that the simulation is concentrated on reducing the Temperature at nose. Thus, spike is introduced for the same model and for same input and successfully found reduction in nose temperature compared to without spike one. The following figures shows the mesh model four different designs of tip of the spike.

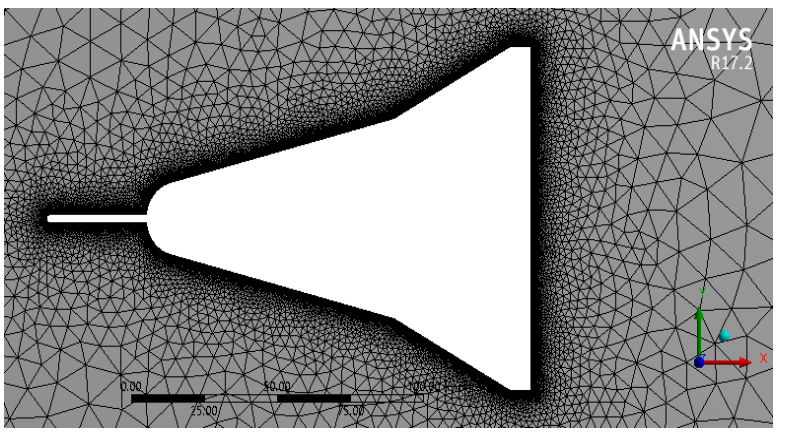

Figure 9. Mesh Model of Blunt Spike Vehicle

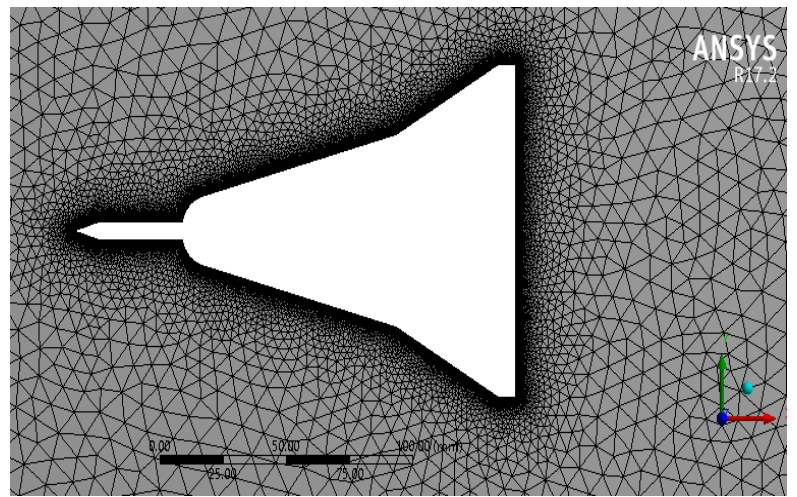

Figure 10. Mesh Model of Slender Spike Vehicle

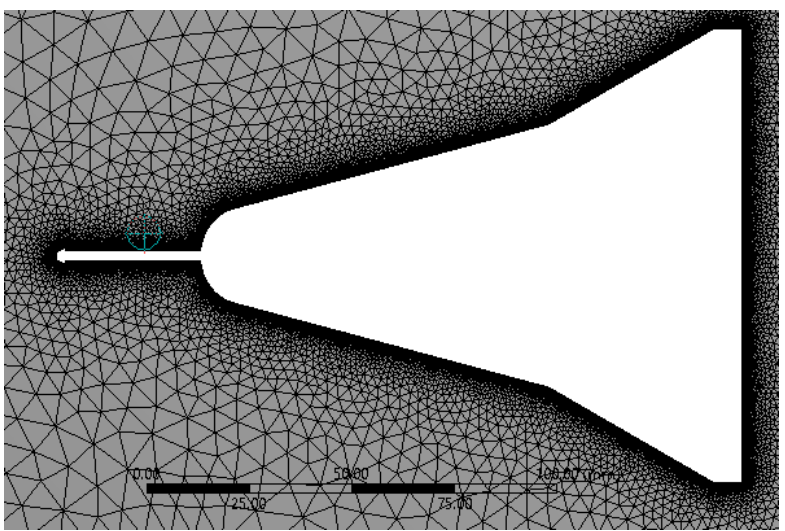

Figure 11. Mesh Model of Snap Spike Vehicle

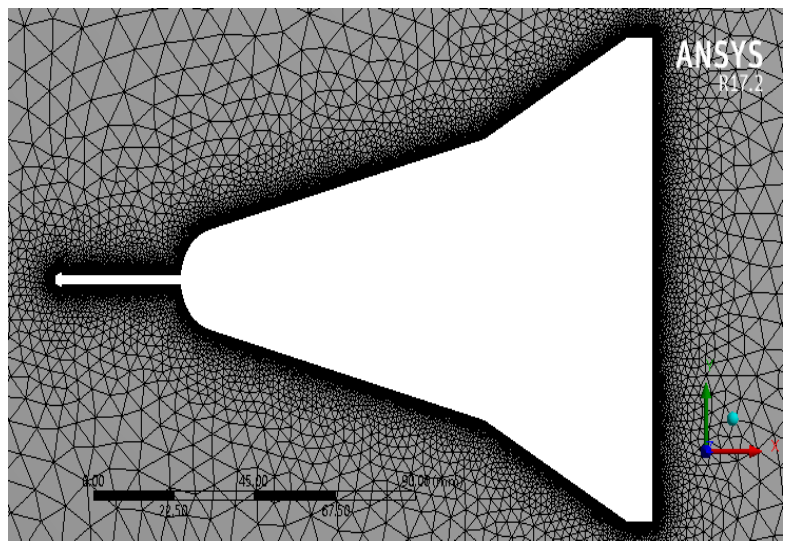

Figure 12. Mesh Model of Pan Spike Vehicle

By changing the form and geometry of spikes its effect on presentation is evaluated, during this study, the form optimisation of two categories of spikes has been studied: A spike with tip as slender \& blunt (figure $9 \&$ 10). On one facet, slender spike style reduces the drag however a lot of heating. On the opposite facet, blunt spike style produces a lot of drag. However they're choosable as aero heating reduces. To avoid intense shocks thereby minimizing the temperature, spikes are built at the nose region.

Modeling, Meshing \& Fluent analysis is performed in same way as that of without spike model for the same boundary conditions. A spike of four designs was modelled at the frontal region of the high speed vehicle. Blunt spike with $40 \mathrm{~mm}$ length and having blunt radius at tip of $3 \mathrm{~mm}$. slender spike of length $40 \mathrm{~mm}$ and having slender angle at tip of $17.06^{\circ}$. The spike length is same for Snap spike (figure 11) with radius equal to $4 \mathrm{~mm}$. Similarly,Pan spike (Figure 12) is having a slender angle of $17.06^{\circ}$ with slant length $4.47 \mathrm{~mm}$. 


\section{RESULTS AND DISCUSSION}

\subsection{Blunt Spiked Vehicle}

For Blunt, spiked body the following pressure profile and Temperature profile is analyzed (figure $13 \& 14$ ). The temperature observed for the high speed Blunt spike vehicle was $812 \mathrm{~K}$ (figure 15). Due to the spike the generated shock wave scatters away and gradually lowers temperature along structure of vehicle.

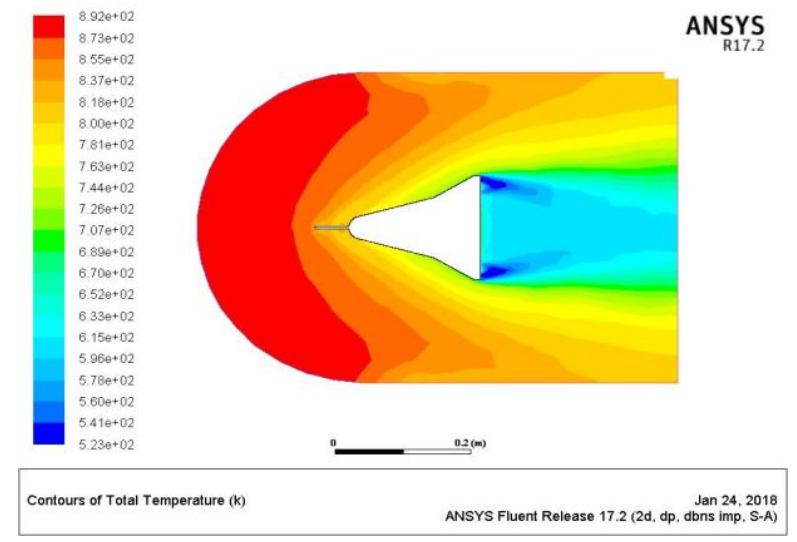

Figure 13. Temperature Contour of Blunt Spike Body

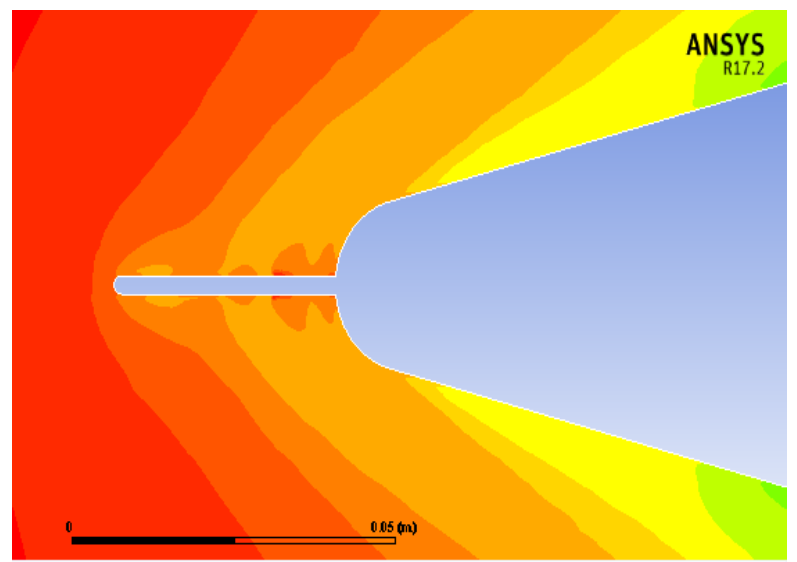

Figure 14 Enlarged View of Temperature profile

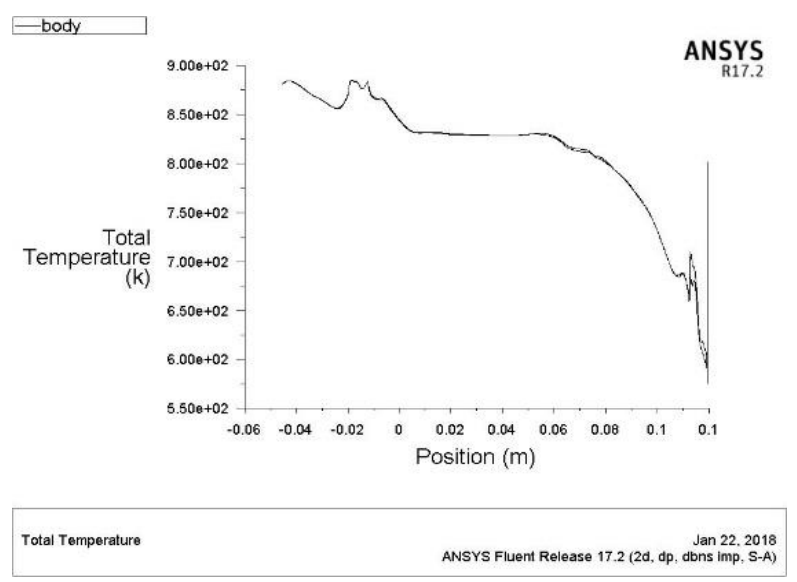

Figure 15 Temperature plot of Blunt Spiked Vehicle

\subsection{Slender Spiked Vehicle}

For slender spiked body Temperature profile is shown in figure $16 \& 17$. The temperature observed for the slender spiked vehicle was $848 \mathrm{k}$.(figure 18)

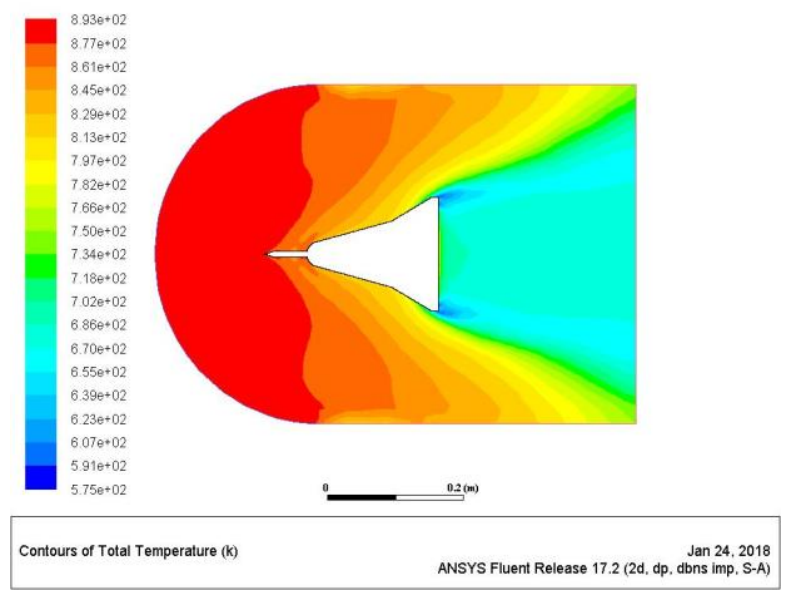

Figure 16 Temperature Contour of Slender Spike Vehicle

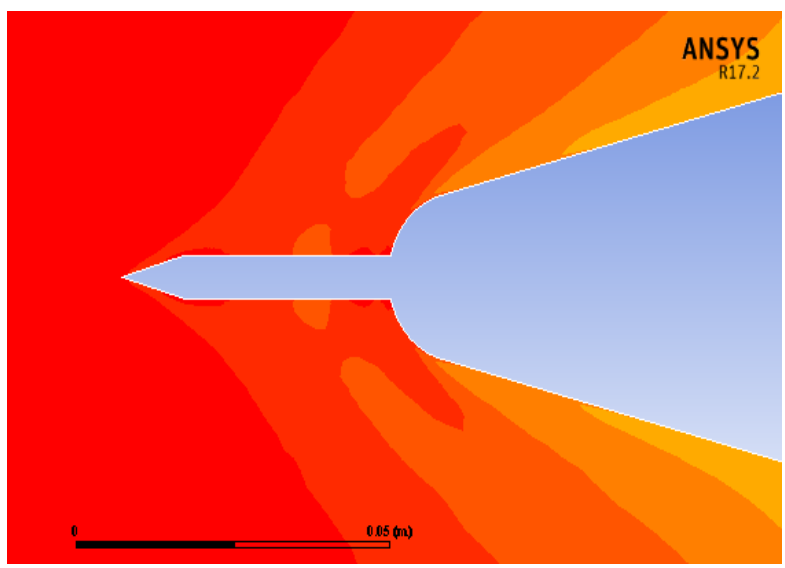

Figure 17 Enlarged View of Temperature profile

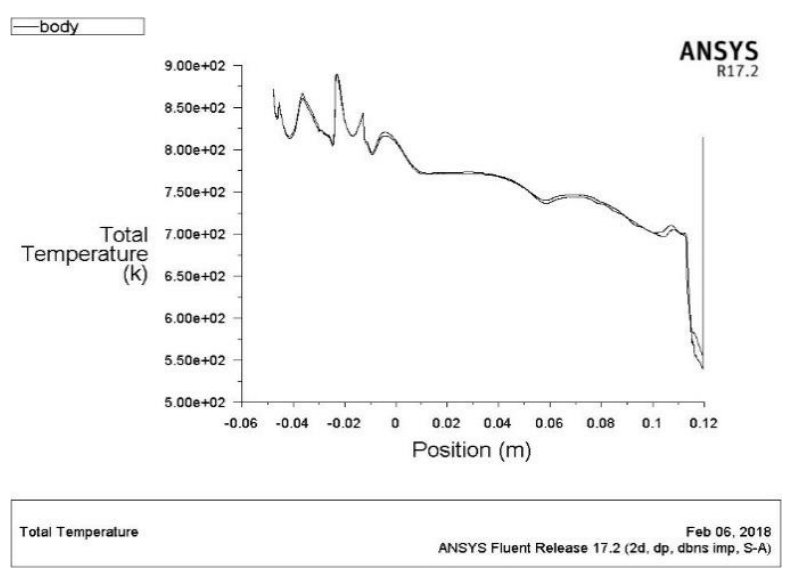

Figure 18 Temperature plot of Slender Spiked Vehicle

\section{.5.3 Snap Spiked Vehicle}

For Snap spiked body the analysed Temperature profile is shown in the figure $19 \& 20$. The temperature computed for the snap vehicle was $820 k$.(figure 21) 


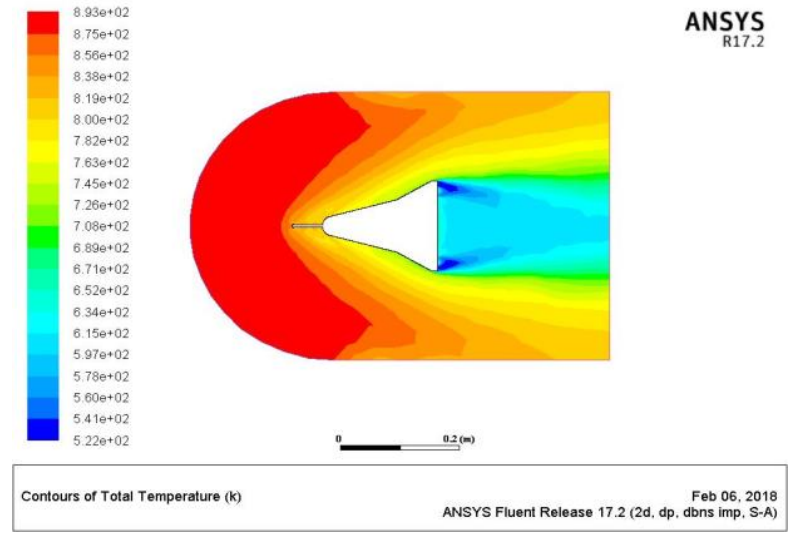

Figure 19 Temperature Contour of Snap Spiked Vehicle

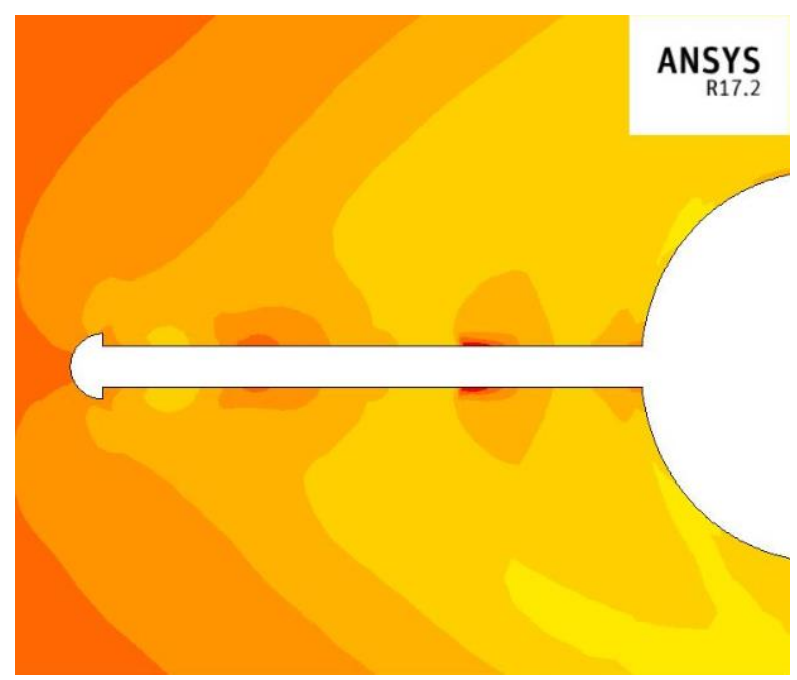

Figure 20 Enlarged View of Temperature profile

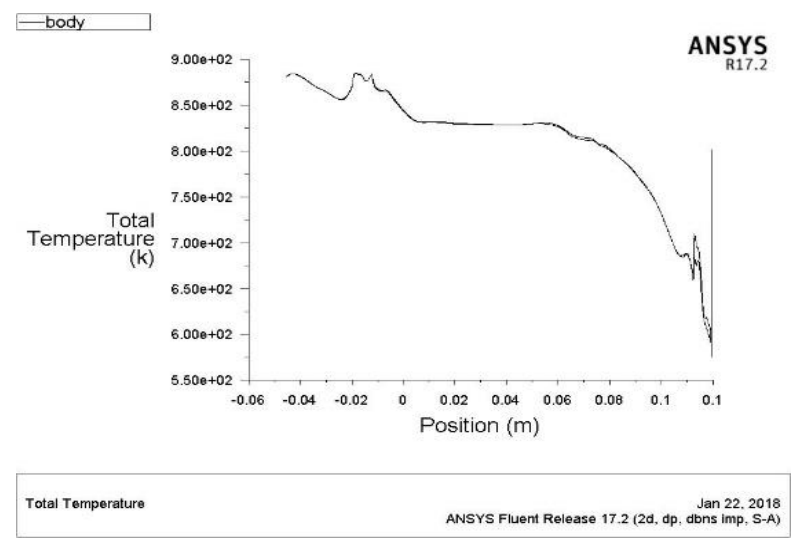

Figure 21 Temperature plot of Snap Spiked Vehicle.

\subsection{Pan Spiked Vehicle}

The temperature computed for the snap spiked vehicle was $820 \mathrm{~K}$ (figure 24).It can be clearly observed in the figure $22 \& 23$.

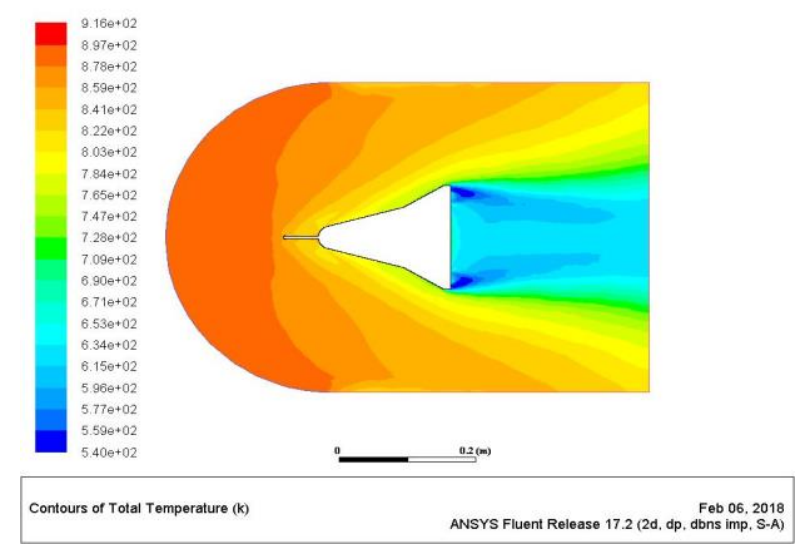

Figure 22 Temperature Contour of Pan Spiked Vehicle

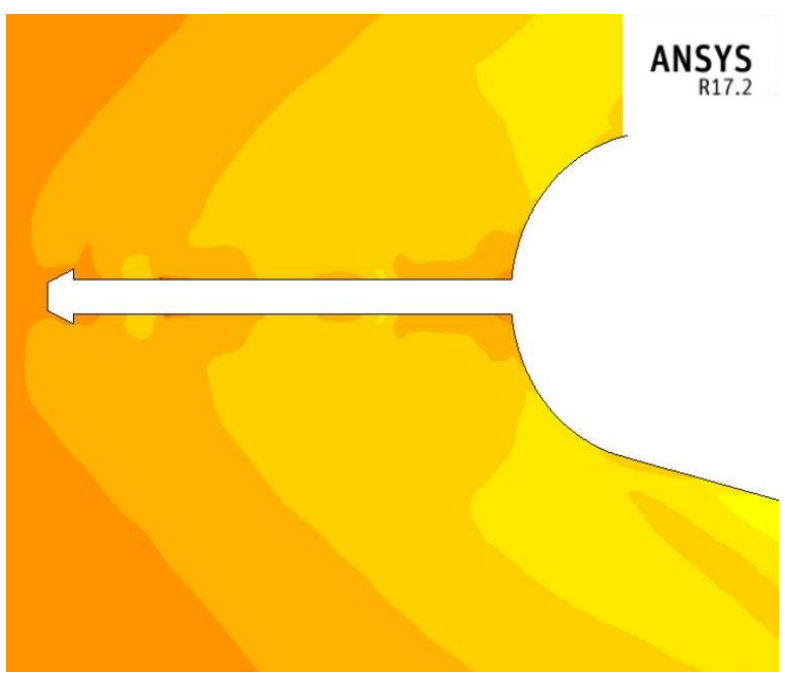

Figure 23 Enlarged View of Temperature profile

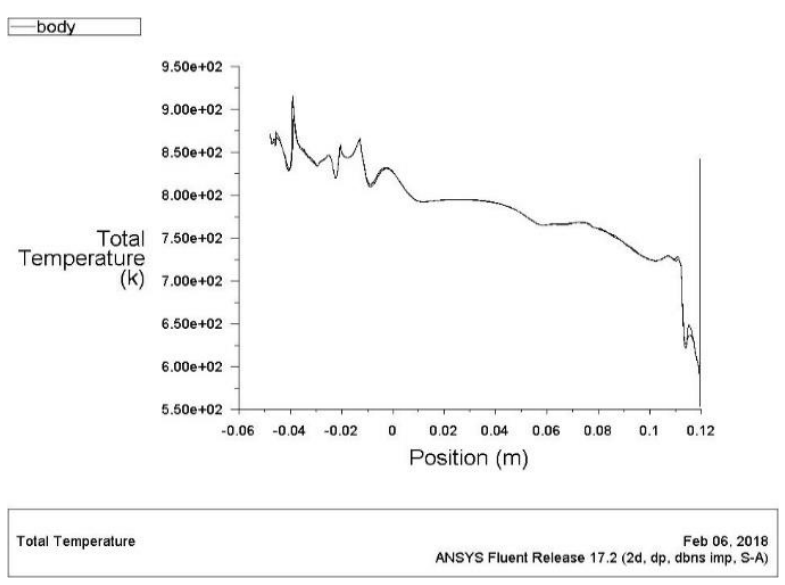

Figure 24 Temperature plot of Snap Spiked Vehicle.

The figure 25 shows temperatures of without spike and with spiked vehicle that includes Blunt, Slender, Snap, and Pan Spike respectively with respect to their corresponding positions. Clearly, the nose region of without spiked vehicle is at a higher temperature than that of its other parts. However, there isn't much reduction of temperature throughout the body .In addition, spiked vehicles has showed a better response in the reduction of temperature especially at the nose. 


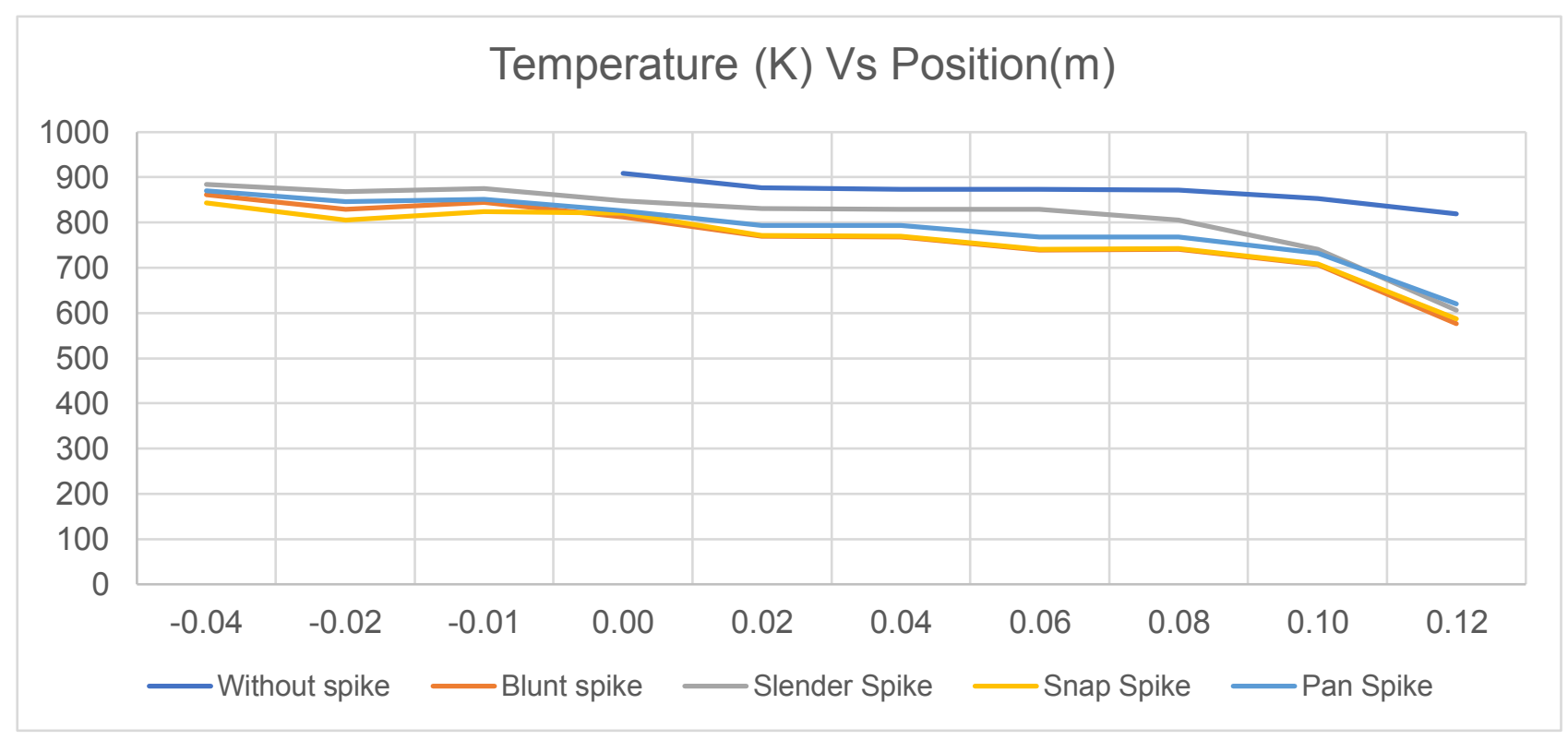

Figure 25 Temperature Comparison of Blunt, Slender, Snap and Pan and without spike

Moreover, blunt spike vehicle is much more effective followed by Snap spike then by Pan Spike. The slender one was least effective which shows similar trend as of without spike vehicle and was below it.

\section{CONCLUSION}

Keeping in view of future requirements for Hypersonic field of research as well as to generate data base towards extending some of existing static temperature, correlations, a detailed CFD study of hypersonic laminar surface flows on several spiked models will have relevance to reentry missions.

In this paper, design and optimization for the reentry vehicle in hypersonic flight regime at Mach no 9.1 is carried out. While analyzing the Blunt, Slender, Snap and Pan shaped spikes, it is noticed that by introducing Blunt spike there is $13 \%$ reduction of heat at the nose, slender spike is around $7.5 \%$, Snap spike is around $11 \%$ and Pan spike is around $9.5 \%$ when compared with the without spike model. Finally, it can be concluded that as a result of spikes heat is reduced at nose. The Slender \& Pan spiked vehicles have comparatively less heat reduction than with Snap \& Blunt spiked vehicles. So, Blunt and Snap spikes are comparatively preferable over two.

\section{REFERENCES}

[1]F.J Schrijer Ferry and Fulvio Scarano and W. Bas. Van Oudheusden, Hypersonic Boundary Layer Separation and Reattachment on a Blunted ConeFlare using Quantitative Infrared Thermography, AIAA International Space Planes and Hypersonic Systems and Technology 6967 pp.1-8 (2003)

[2] Jiang Zonglin and Liu Yunfeng and Han Guilai, A new concept of the Non-ablative Thermal Protection System (NATPS) for hypersonic vehicles, 51, pp. 584-590 (2013).
[3] D. Dirkx, E. Mooij, Optimization of entry-vehicle shapes during conceptual design, Acta Astronautica 94, pp.198-214 (2014)

[4] P. Harish, K. Rajagopal, Aero thermodynamic Design optimization of a hypersonic winged reentry vehicle using CFD, International Journal of Engineering and Technology 3 pp. 1-8 (2014).

[5] P. Harish, H N. Naveen and Dr. K Rajagopal, Recent advancements in aerothermodynamic Design Optimization of Spiked hypersonic Winged Re-Entry Vehicle using CFD,International Journal of Engineering Research \& Technology 3 ,pp. 877-882. (2014).

[6] Y.Y. Zeng and N.A. Ahmed, Computational fluid dynamics investigation of counter flow ejection effects on a body moving with high speed, Proceedings International Conference on Mechanical Engineering and Material Science 27, pp.410-413 (2012).

[7] C.N.Nataraj and H. Manjunatha, Aerothermodynamic Design and Optimisation of Hypersonic Research Reentry Vehicle, International Journal of Science and Research $\mathbf{3}$, pp.1234-1238 (2014).

[8] A. Peter Gnoffo, K. James Weilmuenster, H. Harris, Computational Aerothermodynamics design issues for Hypersonic Vehicles, AIAA 36, pp.1108-1113 (2001).

[9] P. A. Gnoffo, Planetary-entry Gas Dynamics, Annual Review of Fluid Mechanics 31(2001).pp. 459-494.

[10] E.H. Hirschel, C. Wieland, Selected Aerothermodynamic Design Problems of Hypersonic Flight Vehicles, International Journal of Computational Fluid Dynamics, 25, pp. 74-86 (2009).

[11] M. Grant, I. Clark, R. Braun, Rapid Simultaneous Hypersonic Aerodynamic and Trajectory Optimization Using Variational methods, Conference AIAA Atmospheric Flight Mechanics, 6640 (2011). 
[12] D. J. Kinney, Aero-Thermodynamics for Conceptual Design, 42nd AIAA Aerospace Sciences Meeting and Exhibit, Reno, Nevada, January (2004)

[13] Sahoo Niranjan, S. Saravanan, Jagadeesh, K P J Reddy, Simultaneous measurement of aerodynamic and heat transfer data for large angle blunt cones in hypersonic shock tunnel, Sädhanā
Academy Proceedings in Engineering Sciences 31 , pp. 557-581 (2006).

[14] John. D. Anderson, Jr. Computational Fluid Dynamics, (McGraw-Hill Book Co., International Editions, 1995).

[15] Versteeg H. K. and Malalasekara W., Introduction to Computational Fluid Dynamics, (Long Man Group Ltd., 1995). 